\title{
$\widehat{A}$ Madridge
}

madridge Journal of Women's Health and Emancipation

\author{
Interconnecting Scientific World
}

Research Article

Open Access

\section{Perceptions of Perinatal Anxiety, Depression, and Mental Health treatment in a Low-Income, Latina Population}

\author{
Jamie Lim Lacsina ${ }^{1 \star}$, Vivian Tang ${ }^{1}$, Kate Wolitzky-Taylor ${ }^{2}$, Doerthe Brueggmann ${ }^{3}$, Jenny Jaque ${ }^{3}$ and Emily C Dossett ${ }^{1}$ \\ ${ }^{1}$ Department of Psychiatry, University of Southern California, USA \\ ${ }^{2}$ Department of Psychiatry and Biobehavioral Sciences, Semel Institute, University of California, Los Angeles, USA \\ ${ }^{3}$ Department of Obstetrics and Gynecology, University of Southern California, USA
}

Article Info

*Corresponding author:
Jamie Lim Lacsina
Department of Psychiatry
University of Southern California
2250 Alcazar St. \#2200
Los Angeles, CA 90033
USA
Tel: 323-226-5555
E-mail: jllacsina@gmail.com

Received: September 1, 2017

Accepted: September 18, 2017

Published: September 22, 2017

Citation: Lacsina JL, Tang VK, Wolitzky-Taylor K, Brueggmann D, Jaque J, Dossett EC. Perceptions of Perinatal Anxiety, Depression, and Mental Health treatment in a Low-Income, Latina Population. Madridge J Womens Health Emancipation. 2017; 1(1): 22-28.

doi: $10.18689 / \mathrm{mjwh}-1000106$

\begin{abstract}
Copyright: ๑ 2017 The Author(s). This work is licensed under a Creative Commons Attribution 4.0 International License, which permits unrestricted use, distribution, and reproduction in any medium, provided the original work is properly cited.
\end{abstract}

Published by Madridge Publishers

\begin{abstract}
This study examined the perceptions of Latina women regarding perinatal mental health and its treatment. Ninety-five women completed a 60-item Perinatal Mental Health Questionnaire (PMHQ). Responses to items were compared between women who completed the questionnaire in English versus Spanish. In regards to the effects of anxiety or depression on the fetus or breastfeeding infant, both English and Spanish participants expressed concern over potential high levels of harm. Despite this, both groups viewed psychotropic medication during the perinatal period to be unsafe. There was a significant difference when it came to therapy $(p<0.001)$, with those completing Spanish questionnaires finding therapy during pregnancy to be less acceptable. A clear gap existed between the perceived high risks of untreated perinatal depression or anxiety and the low acceptability of mental health services. Understanding these results may lead to increased treatment rates and improve long-term health outcomes for both Latina mothers and their infants.
\end{abstract}

Keywords: Perinatal anxiety; Depression; Latina; Low income; Postpartum depression.

\section{Introduction}

Perinatal depression and anxiety disorders are associated with adverse long-term health effects for both mothers and infants [19, 30]. As a result, improving mental health interventions during this critical time period may have important consequences for women and their children. A systematic review of studies predominantly performed in high-income countries estimated the prevalence of major depressive disorder to be between $3.1 \%$ and $4.9 \%$ during pregnancy and $4.7 \%$ in the first three months postpartum. When minor depression was included, prevalence was estimated to be up to $11 \%$ in pregnancy and $13 \%$ in the first three months post-partum [13]. In terms of anxiety, a study done in the U.S. found a prevalence of $13 \%$ of anxiety disorder in pregnant women or post-partum women in the past year [35]. In addition, up to onethird of women experiencing postpartum depression also meet criteria for postpartum anxiety disorder, suggesting significant comorbidity rates [28]. According to a 2010 U.S. Census report, more than half of the growth in the total population of the United States between 2000 and 2010 was due to the increase in the Latino population [9]. Although research has been limited, studies of perinatal Latinas have reported prevalence of high depressive symptoms to be between $15-31 \%[6,17]$. 
Evidence-based treatments exist for postpartum depression [19]. A Cochrane review showed that psychosocial and psychological interventions were effective for reducing depression symptoms within the first year postpartum [7]. Antidepressants have been shown to be especially effective in severe cases of perinatal depression, and a meta-analysis found that the efficacy of antidepressants increased with the severity of depression $[12,19]$. Good evidence exists for the effectiveness of non-pharmacological treatment during the antenatal period, including cognitive-behavioral therapy and interpersonal psychotherapy [19]. Despite the existence of these treatments, studies have shown that a low percentage of women with depression actually receive any interventions during pregnancy or the postpartum period $[14,18]$.

Matching patients with their preferred treatment for depression is associated with a more rapid improvement in depression symptomatology [26]. Several studies have looked at preferences and attitudes regarding treatment for depression and demonstrated that women with depression prefer non-pharmacological intervention over antidepressants $[8,14,33]$. Research shows that minority women have less preference for SSRIs than U.S.-born Caucasian women [1, 5, 27] and group therapy endorsement is high among immigrant Latinas [27]. A qualitative study by Lara-Cinisomo et al. specifically looked at perinatal depression treatment preferences among Latina mothers. Results showed that preferences consisted of a pathway approach. This began with the use of one's own resources followed by the use of formal support systems and supplemented by the use of behavioral therapy. Antidepressant use was seen to be acceptable only in severe cases [24].

Because there have been few studies on the preferences of women, especially Latinas, regarding treatment for perinatal anxiety or depression, more research is needed. This study seeks to add to existing literature by examining perceptions of perinatal anxiety, depression, and mental health treatment in a low-income, Latina population at Los Angeles County + USC Medical Center (LAC+USC). LAC+USC Medical Center is one of the largest public hospitals in the United States, and it provides healthcare services for the region's medically underserved. The majority of patients at LAC+USC are Latino, many of whom are Mexican or from Central America. A significant proportion of patients at LAC+USC, of all ethnic and racial backgrounds, are facing stressors of poverty, trauma, and fractured social support systems. As a result, these individuals are at an increased risk of developing mental health concerns.

\section{Methods}

\section{Sample}

Participants were recruited from an outpatient OB-GYN/ prenatal clinic at Los Angeles County + USC Medical Center. They included women seeking obstetric and gynecological care who were both pregnant and not pregnant. Detainees as well as minors were excluded. As the study is regarding perinatal mental illness, male participants were also excluded.
Finally, because the questionnaire was only provided in English and Spanish, those who could not read or understand either of these languages were excluded. University of Southern California Health Science Campus Institutional Review Board approval was received, and informed consent was obtained from all participants.

\section{Perinatal Mental Health Questionnaire}

Participants were asked to complete a 60-item questionnaire to assess their knowledge and understanding of perinatal depression and anxiety. The questionnaire also contained items that addressed personal psychiatric history and past medical history as well as basic demographics such as age and ethnicity. After the researchers developed the items, they were further refined using two focus groups. Recruitment of focus groups, consisting of a minimum of ten participants, aimed to represent diversity in age and educational backgrounds. The first focus group was asked to give feedback on the clarity of items. The revised questionnaire was then sent to a second focus group for final feedback. The questionnaire was then translated into Spanish.

Questionnaires were distributed by a medical student who was uninvolved in patient care. Patients waiting in the prenatal care clinic waiting room were asked if they wanted to participate in the study. If they indicated that they did, they were given a study information sheet explaining the purpose of the study and that their choice to participate would not affect their care (these were in English and Spanish). The medical student was available to answer any questions regarding the questionnaire. After completing the survey, patients returned it to the medical student who placed completed surveys in a secure box.

\section{Screening for Anxiety and Depression}

In addition to the 60-item Perinatal Mental Health Study Questionnaire, participants were also asked to complete the Patient Health Questionnaire 9-item (PHQ-9) and Generalized Anxiety Disorder 7-item (GAD-7), which are validated screening tools for depression and anxiety, respectively. Based on a well-known systematic review published by Kroenke et al., cut points of 5, 10, and 15 were used to represent mild, moderate, and severe symptom levels on the PHQ-9 and GAD-7 [22]. We used a cut point of 5 to include women with mild symptoms of depression or anxiety in our analyses. Upon completion of the PHQ-9, the medical student evaluated each survey for signs of suicide risk. If there was any concern for suicidality, a mental health professional was immediately notified and the patient evaluated. Of note, all women who receive care at the LAC+USC outpatient OB-GYN clinic where this study took place are screened for anxiety and depression. This screening did not impact the selection of women to participate in the study. Mental healthcare services and social support are provided to all those who demonstrate need.

\section{Measuring Perceptions}

To measure perceptions regarding medication use during pregnancy, we calculated a composite score based on responses to Questions $1 \mathrm{M}-3 \mathrm{M}$ (Table 1). Similarly, we derived 
composite scores for perceptions regarding therapy during pregnancy (Table 2) as well as understandings of the effects of anxiety or depression on the developing fetus and infant (Table 3).

Table 1: Calculation of composite score for medication perceptions

\begin{tabular}{|c|c|}
\hline $\begin{array}{l}1 \mathrm{M} \text {. How likely would you be willing to start } \\
\text { medication for anxiety or depression while pregnant? }\end{array}$ & $\begin{array}{c}\text { 1=Very Likely, } \\
2=\text { Most likely, } \\
3=\text { Somewhat Likely, } \\
4=\text { Not Likely }\end{array}$ \\
\hline $\begin{array}{l}\text { 2M. In your opinion, how safe are medications for } \\
\text { anxiety and depression in pregnancy? }\end{array}$ & $\begin{array}{c}\text { 1=Very Safe, } \\
2=\text { Somewhat Safe, } \\
\text { 3=A Little Safe, } \\
\text { 4=Not Safe at All }\end{array}$ \\
\hline $\begin{array}{l}\text { 3M. In your opinion, how safe are medications for } \\
\text { anxiety and depression while breastfeeding? }\end{array}$ & $\begin{array}{c}\text { 1=Very Safe, } \\
2=\text { Somewhat Safe, } \\
\text { 3=A Little Safe, } \\
\text { 4=Not Safe at All }\end{array}$ \\
\hline
\end{tabular}

For each participant, a medication perceptions score was calculated by taking the sum of responses to Questions $1 \mathrm{M}-3 \mathrm{M}$.For example, if a participant answered "Very Likely" to $1 \mathrm{M}$, "Somewhat Safe" to $2 \mathrm{M}$, and "A Little Safe" to 3M, her composite score would be $1+2+3=6$

Table 2: Calculation of composite score for therapy perceptions

\begin{tabular}{|c|c|}
\hline $\begin{array}{c}\text { 1T. How likely is it that you would engage in therapy } \\
\text { for treatment of your anxiety or depression while } \\
\text { pregnant? }\end{array}$ & $\begin{array}{c}1=\text { Very Likely, } \\
2=\text { Most likely, } \\
3=\text { Somewhat Likely, } \\
\text { 4=Not Likely }\end{array}$ \\
\hline $\begin{array}{c}\text { 2T. How acceptable is it for you to seek individual } \\
\text { counseling? }\end{array}$ & $\begin{array}{c}1=\text { Definitely } \\
\text { Acceptable, 2=Mostly } \\
\text { Acceptable, 3=Maybe } \\
\text { Acceptable, 4=Never } \\
\text { Acceptable }\end{array}$ \\
\hline 3T. How acceptable is it for you to seek group \\
counseling? & $\begin{array}{c}1=\text { Definitely } \\
\text { Acceptable, 2=Mostly } \\
\text { Acceptable, 3=Maybe } \\
\text { Acceptable, 4=Never } \\
\text { Acceptable }\end{array}$ \\
\hline
\end{tabular}

For each participant, a therapy perceptions score was calculated by taking the sum of responses to Questions 1T-3T.For example, if a participant answered "Very Likely" to 1T, "Definitely Acceptable" to 2T, and "Maybe Acceptable" to 3T, her composite score would be $1+1+3=5$

Table 3: Calculation of composite score for fetal/infant harm perceptions

\begin{tabular}{|c|c|}
\hline $\begin{array}{c}\text { 1F. How much does anxiety or depression in pregnancy } \\
\text { harm the baby in the womb? }\end{array}$ & $\begin{array}{c}1=\text { Very Much, } \\
2=\text { Somewhat, 3=A } \\
\text { Little Bit, 4=Not at All }\end{array}$ \\
\hline $\begin{array}{c}\text { 2F. How much does anxiety or depression in a new } \\
\text { mother harm the baby if he/she is breastfeeding? }\end{array}$ & $\begin{array}{c}1=\text { Very Much, } \\
2=\text { Somewhat, 3=A } \\
\text { Little Bit, 4=Not at All }\end{array}$ \\
\hline
\end{tabular}

For each participant, a fetal/infant harm perceptions score was calculated by taking the sum of responses to Questions $1 \mathrm{~F}$ and $2 \mathrm{~F}$.For example, if a participant answered "Very Much" to $1 \mathrm{~F}$ and "A Little Bit" to $2 \mathrm{~F}$, her composite score would be $1+3=4$

The internal consistencies of the created composite scores representing "medication perceptions, "therapy perceptions," and "fetal/infant harm" ranged from acceptable to excellent, with Cronbach's $\alpha=0.71,0.63$, and 0.84 , respectively.

\section{Analyses}

Analyses were performed using SPSS version 22. T-tests and ANCOVAs were used to examine between-group (i.e., survey language) differences on continuous variables. Specifically, $t$-tests were conducted with language of the survey (English v. Spanish) as the independent variable and the medication perceptions score, therapy perceptions score, and fetal/infant harm perceptions score as the dependent variables. Next, a series of ANCOVAs were performed with survey language as the independent variable and the aforementioned composite scores as the dependent variables. Age, pregnancy status (yes v. no), and current anxiety or depression status (yes v. no) were covariates. This follow-up ANCOVA was conducted to determine whether survey language had a significant effect on the composite scores after accounting for variance explained by these potential confounding variables (age, pregnancy status, current anxiety/ depression status).

\section{Results}

A total of 100 women consented to participate in our study, with 95 completing the Perinatal Mental Health Study Questionnaire. The majority of our sample was Latina (75.8\%). Of those born outside of the U.S. (60.1\%), the majority was born in Mexico (57.9\%) followed by El Salvador (12.3\%). Of the 51 participants who completed the questionnaire in English, 3.9\% screened positive for severe depression (PHQ-9 $\geq 15$ ). Of the 44 participants who completed the questionnaire in Spanish, $4.5 \%$ screened positive for severe depression (PHQ-9 $\geq 15$ ). Sample descriptive statistics are summarized in Table4.

Table 4: Sample Descriptive Statistics

\begin{tabular}{|l|c|c|}
\hline & \multicolumn{2}{|c|}{ N = 95 } \\
\hline Characteristics & N & $\%$ \\
\hline Ethnicity & & \\
\hline Caucasian, non-Hispanic & 6 & 6.3 \\
\hline African-American & 4 & 4.2 \\
\hline Latino & 72 & 75.8 \\
\hline Asian & 1 & 1.1 \\
\hline Other (Multiracial) & 8 & 8.4 \\
\hline None indicated & 4 & 4.2 \\
\hline Born in United States & & \\
\hline Yes & 35 & 36.8 \\
\hline No & 57 & 60.1 \\
\hline No answer & 3 & 3.1 \\
\hline Pregnancy Status & & \\
\hline Yes & 65 & 68.4 \\
\hline No & 21 & 22.1 \\
\hline No answer & 9 & 9.5 \\
\hline Completed Survey in English & 51 & 53.7 \\
\hline Completed Survey in Spanish & 44 & 46.3 \\
\hline Screened Positive for Anxiety & 25 & 26.3 \\
\hline Screened Positive for Depression & 26 & 27.4 \\
\hline Screened Positive for Anxiety and Depression & 19 & 20.0 \\
\hline & \multicolumn{2}{|c|}{ M \pm SD } \\
\hline Age & $31 \pm 8$ \\
\hline
\end{tabular}

Table 5 shows the percentage distributions of responses to questionnaire items used to derive the medication perceptions score (Table 1), therapy perceptions score (Table 2), and fetal/infant harm perceptions score (Table 3). 
Table 5: Percentage Distributions of Responses to Items Used to Calculate the Medication Perceptions Score (1M-3M), Therapy Perceptions Score (1T-3T), and Fetal/Infant Harm Perceptions Score $(1 \mathrm{~F}-2 \mathrm{~F})$

\begin{tabular}{|c|c|c|c|c|c|}
\hline & & Very Likely & Most likely & $\begin{array}{l}\text { Somewhat } \\
\text { Likely }\end{array}$ & Not Likely \\
\hline \multirow{3}{*}{\begin{tabular}{|c|}
$1 \mathrm{M}$. How likely \\
would you be willing \\
to start medication \\
for anxiety or \\
depression while \\
pregnant? \\
\end{tabular}} & $\begin{array}{l}\text { English } \\
(\%)\end{array}$ & 4.3 & 17.0 & 17.0 & 61.7 \\
\hline & $\begin{array}{c}\text { Spanish } \\
(\%)\end{array}$ & 2.3 & 4.7 & 18.6 & 74.4 \\
\hline & & Very Safe & $\begin{array}{l}\text { Somewhat } \\
\text { Safe }\end{array}$ & $\begin{array}{l}\text { A Little } \\
\text { Safe }\end{array}$ & $\begin{array}{c}\text { Not Safe } \\
\text { at All }\end{array}$ \\
\hline \multirow{3}{*}{$\begin{array}{l}2 \mathrm{M} . \text { In your } \\
\text { opinion, how safe } \\
\text { are medications } \\
\text { for anxiety and } \\
\text { depression in } \\
\text { pregnancy? }\end{array}$} & $\begin{array}{l}\text { English } \\
(\%)\end{array}$ & 4.2 & 8.3 & 18.7 & 68.8 \\
\hline & $\begin{array}{c}\text { Spanish } \\
(\%)\end{array}$ & 2.5 & 15.0 & 30.0 & 52.5 \\
\hline & & Very Safe & $\begin{array}{l}\text { Somewhat } \\
\text { Safe }\end{array}$ & $\begin{array}{l}\text { A Little } \\
\text { Safe }\end{array}$ & $\begin{array}{c}\text { Not Safe } \\
\text { at All }\end{array}$ \\
\hline \multirow{3}{*}{$\begin{array}{c}\text { 3M. In your } \\
\text { opinion, how safe } \\
\text { are medications } \\
\text { for anxiety and } \\
\text { depression while } \\
\text { breastfeeding? }\end{array}$} & $\begin{array}{c}\text { English } \\
(\%)\end{array}$ & 0.0 & 14.6 & 10.4 & 75.0 \\
\hline & $\begin{array}{c}\text { Spanish } \\
(\%)\end{array}$ & 5.0 & 15.0 & 22.5 & 57.5 \\
\hline & & Very Likely & Most likely & $\begin{array}{c}\text { Somewhat } \\
\text { Likely }\end{array}$ & Not Likely \\
\hline \multirow{3}{*}{$\begin{array}{c}1 \mathrm{~T} \text {. How likely is } \\
\text { it that you would } \\
\text { engage in therapy } \\
\text { for treatment of your } \\
\text { anxiety or depression } \\
\text { while pregnant? }\end{array}$} & $\begin{array}{l}\text { English } \\
(\%)\end{array}$ & 35.5 & 26.7 & 17.8 & 20.0 \\
\hline & $\begin{array}{c}\text { Spanish } \\
(\%)\end{array}$ & 11.6 & 7.0 & 41.9 & 39.5 \\
\hline & & $\begin{array}{c}\text { Definitely } \\
\text { Acceptable }\end{array}$ & $\begin{array}{c}\text { Mostly } \\
\text { Acceptable }\end{array}$ & $\begin{array}{c}\text { Maybe } \\
\text { Acceptable }\end{array}$ & $\begin{array}{c}\text { Never } \\
\text { Acceptable }\end{array}$ \\
\hline \multirow{3}{*}{$\begin{array}{l}\text { 2T. How acceptable } \\
\text { is it for you to } \\
\text { seek individual } \\
\text { counseling? }\end{array}$} & $\begin{array}{l}\text { English } \\
\text { (\%) }\end{array}$ & 63.8 & 21.3 & 8.5 & 6.4 \\
\hline & $\begin{array}{c}\text { Spanish } \\
(\%)\end{array}$ & 29.3 & 21.9 & 41.5 & 7.3 \\
\hline & & $\begin{array}{c}\text { Definitely } \\
\text { Acceptable }\end{array}$ & $\begin{array}{c}\text { Mostly } \\
\text { Acceptable }\end{array}$ & $\begin{array}{c}\text { Maybe } \\
\text { Acceptable }\end{array}$ & $\begin{array}{c}\text { Never } \\
\text { Acceptable }\end{array}$ \\
\hline \multirow{3}{*}{$\begin{array}{l}\text { 3T. How acceptable } \\
\text { is it for you to seek } \\
\text { group counseling? }\end{array}$} & $\begin{array}{c}\text { English } \\
(\%)\end{array}$ & 46.8 & 14.9 & 27.7 & 10.6 \\
\hline & $\begin{array}{c}\text { Spanish } \\
(\%)\end{array}$ & 22.0 & 19.5 & 46.3 & 12.2 \\
\hline & & Very Much & Somewhat & A Little Bit & Not at All \\
\hline \multirow{3}{*}{$\begin{array}{c}\text { 1F. How much does } \\
\text { anxiety or depression } \\
\text { in pregnancy harm } \\
\text { the baby in the } \\
\text { womb? }\end{array}$} & $\begin{array}{c}\text { English } \\
\text { (\%) }\end{array}$ & 57.1 & 24.5 & 10.2 & 8.2 \\
\hline & $\begin{array}{c}\text { Spanish } \\
\text { (\%) }\end{array}$ & 42.9 & 30.9 & 21.4 & 4.8 \\
\hline & & Very Much & Somewhat & A Little Bit & Not at All \\
\hline \multirow{2}{*}{$\begin{array}{l}\text { 2F. How much does } \\
\text { anxiety or depression } \\
\text { in a new mother } \\
\text { harm the baby if he/ } \\
\text { she is breastfeeding? }\end{array}$} & $\begin{array}{l}\text { English } \\
\text { (\%) }\end{array}$ & 53.1 & 26.5 & 12.2 & 8.2 \\
\hline & $\begin{array}{c}\text { Spanish } \\
(\%)\end{array}$ & 38.4 & 41.0 & 10.3 & 10.3 \\
\hline
\end{tabular}

There were no significant differences between women completing the English v. Spanish language surveys on medication perceptions, $p=0.57$. This finding remained nonsignificant after covarying for age, pregnancy status, and anxiety/depression status in an ANCOVA $(p=0.68)$. Notably, none of the covariates were significantly associated with the medication perceptions score (all $p s>0.15$ ).
In contrast, there was a significant difference between English and Spanish language participants on therapy perceptions, $\mathrm{t}(83)=-3.75, p<0.001$. Those completing Spanish language surveys had higher mean composite scores than those completing English language surveys, indicating that those who completed Spanish language surveys found therapy during pregnancy to be less acceptable than those who completed English language surveys. There continued to be a significant difference in therapy perceptions scores (English vs. Spanish) after including the covariates in an ANCOVA, $F(4,77)=8.09, p<0.01$. With all $p s \geq 0.08$, none of the covariates were significantly associated with therapy perceptions score.

Finally, there were no significant differences between women completing surveys in English v. Spanish in regards to the fetal/infant harm perceptions score, $p=0.94$. In terms of the question, "How much does anxiety or depression in pregnancy harm the baby in the womb?" $81.6 \%$ of those completing English surveys and $73.8 \%$ of those completing Spanish surveys responded "Very Much" or "Somewhat" (Table 5). Again, no significant difference remained when covarying for age, pregnancy status, and anxiety/depression status in an ANCOVA ( $p=0.68$ ). In addition, none of the covariates were significantly associated with the fetal/infant harm perceptions score (all $p s>0.11$ ).

\section{Discussion}

In summary, there was a significant difference between English versus Spanish language groups regarding therapy perceptions, with those who completed Spanish language surveys finding therapy during pregnancy to be less acceptable than those who completed English language surveys. In contrast, there was no difference in language groups regarding medication perceptions. Similarly, there was no significant difference in the perception of the effects of anxiety or depression on the fetus or breastfeeding infant. Both English and Spanish participants endorsed concern about potential high levels of harm.

In our study, 3.9\% of the English questionnaire group and $4.5 \%$ of the Spanish questionnaire group screened positive for severe depressive symptoms (PHQ-9 $\geq 15$ ). These rates were much lower than the range of $15-31 \%$ of high depressive symptoms that have been reported in other studies focusing on Latinas $[6,17]$. One reason for these differences could be the use of different depression scales. The Beck Depression Inventory and Center for Epidemiologic Studies Depression (CES-D) have been used in addition to the PHQ-9 to assess perinatal depression. When looking at these three measures, the number of items as well as cut-off scores corresponding to mild, moderate, or severe depression differ $[6,17,23]$.

Another explanation for our findings might be that depression rates vary depending on pregnancy status or stage of pregnancy. In our study, $68.4 \%$ of the women were pregnant, while in a perinatal depression study done by Heilemann et al., only $45.7 \%$ of the sample was pregnant 
versus $54.3 \%$ post-partum [17]. Heilemann et al. found higher rates of severe depression, which could be a reflection of the higher ratio of post-partum to pregnant women in their sample [17]. In our questionnaire, we did not ask pregnant women how many weeks gestation they were; future studies looking at depression across different stages of pregnancy are needed. Overall, because there were so few women who screened positive for severe depressive symptoms in our study, the perceptions regarding medication, therapy, and the effects of anxiety or depression on the fetus/infant reflect those of women who denied depression or who were mildly to moderately depressed. This was confirmed statistically with an ANCOVA that showed that none of our perception scores were significantly associated with the anxiety/depression status of participants.

When therapy perception scores (Table 2) were compared between participants who completed the questionnaire in Spanish versus English, there was a significant difference. Those completing the survey in Spanish found engaging in therapy as well as individual and group therapy less acceptable overall. A study looking at mental health utilization by Latino immigrants reported that one-third of the participants cited the combination of their lack of ability to speak English and service providers' lack of ability to translate into Spanish significantly prevented their help-seeking [3]. In the clinic where this study took place, there were few healthcare providers, let alone mental healthcare providers, who spoke Spanish fluently. In addition, translation for patients is often performed using a phone service. As a result, participants who were not as proficient in English might view therapy as less effective and/or more time-consuming given the lack of Spanish-speaking providers and reliance on phone translation services.

Another possible explanation for our findings is a greater fear of negative consequences as a result of therapy by participants who preferred Spanish versus English. A qualitative study looking at depression care in obstetric settings found that participants were less likely to disclose symptoms of depression and/or intrusive thoughts due to the threat of child protective services and involuntary psychiatric hospitalization [4]. Although we did not ask about immigration status, for our participants who preferred Spanish, deportation might also be a feared consequence of disclosing information, perhaps more so than participants who preferred English. To better understand and interpret our results, we plan to do a follow-up study involving in-depth focus groups with women from the same county outpatient clinic.

When calculated medication perception scores (Table 1) were compared between participants who took the survey in Spanish vs. English, there was no significant difference. This implied that being more fluent in English, and perhaps living in United States longer, did not affect a woman's perception of how safe medications were while pregnant or breastfeeding. This is consistent with studies done in the general population that report pregnant and post-partum women generally find psychotropic medication to be unacceptable $[2$, $29,36]$. Potential reasons for this include mixed messages from the media and care providers regarding the safety of medications in pregnancy. Women might also be concerned about becoming addicted to medication or potential side effects. Finally, the stigma of having a mental illness and having to take medications to control it could also account for the unacceptability of antidepressants.

The greatest proportion of women in both English and Spanish language groups selected "Very Much" when asked how much they believed anxiety or depression harm a developing fetus or baby (Table 5). When fetal/infant harm perception scores (Table 3) were compared between these two groups of participants, there was no significant difference. Both groups' preferences were consistent with current research linking both maternal antenatal and postnatal depression to adverse effects in fetal and childhood development [30]. Symptoms of antenatal depression are associated with an increased risk for premature delivery [15, 16], child emotional problems [25, 34] as well as low levels of general cognitive development, including IQ scores [10, 21]. Postpartum depression has been associated with increased problems with emotional regulation and social behavior in infants $[11,28]$ and adverse development in social, emotional, and cognitive domains in children [20,30,31].

Despite the majority of women in both English and Spanish groups believing that anxiety or depression is harmful to the baby in the womb and during breastfeeding, most of our sample expressed how it would not be likely that they would start medication. There was also reluctance by the Spanish group to engage in therapy as treatment. These findings suggest that women in our study perceived the unacceptability of psychotropic medication or psychotherapy to be greater than the risks of being anxious or depressed while pregnant. This is significant because it implies that women need mental health services that fall outside those traditionally offered in medical settings to address the real dangers they sense from untreated perinatal mood disorders.

One of the biggest limitations of this study was its crosssectional design. As a result, only perceptions at one point of time could be examined and analyzed. To make sure timerelated factors such as a participant's age or pregnancy status were not associated with perception scores, we used ANCOVA analysis to determine if our results still remained significant or non-significant when taking these factors into account. In each case, age and pregnancy status were not associated with composite scores. In addition, formal reliability and validity testing of our questionnaire items was not conducted. Participants were screened for anxiety or depression, however, using well-validated instruments such as the PHQ- 9 and GAD7. To make composite scores better estimates of overall perceptions, more questionnaire items could have been developed and used to calculate composite scores. Despite this, measures of internal consistency for the medication perceptions score, therapy perceptions score, and fetal/infant harm perceptions scores were found to be acceptable or excellent in each case. Finally, only ninety-five women, all of whom were volunteers, were included in our study. Because 
of the small sample size and the fact that strict random sampling was not employed, there could be biases in the data set that limit extrapolation to larger populations.

\section{Conclusions}

Perinatal depression and anxiety can have lifelong consequences for mothers and their infants. In our study, most women in both language groups believed that anxiety or depression is harmful to the developing fetus or infant, but also expressed reluctance to engage in allopathic or psychological mental health services, even when located in a prenatal care clinic. The majority expressed how unlikely they would be to take psychotropic medication while pregnant or breastfeeding. A significant difference between participants who completed our survey in Spanish versus English was found in regards to perceptions of therapy as an intervention for perinatal anxiety or depression. To address this gap between knowledge of illness and treatment acceptability, we plan to do a qualitative study where in-depth focus groups can provide better insight into our findings. It is our hope that this research will help improve perinatal mental health services for Latinas and encourage future collaborations between the fields of psychiatry and obstetrics.

\section{Conflicts of interest, Ethical Approval, Certification of Responsibility}

The authors declare that they have no conflicts of interest. All procedures performed in this study involving human participants were in accordance with the ethical standards of the University of Southern California Health Science Campus Institutional Review Board as well as the 1964 Helsinki declaration and its later amendments. Informed consent was obtained from all individual participants included in this study. All authors certify their responsibility for this manuscript.

\section{References}

1. Alvidrez J, Azocar F. Distressed women's clinic patients: preferences for mental health treatments and perceived obstacles. Gen Hosp Psychiatry. 1999; 21(5): 340-347.

2. Bonari L, Koren G, Einarson TR, Jasper JD, TaddioA, Einarson A. Use of antidepressants by pregnant women: evaluation of perception of risk, efficacy of evidence based counseling and determinants of decision making. Arch Womens Ment Health. 2005; 8(4): 214-220. doi: 10.1007/ s00737-005-0094-8

3. Bridges AJ, Andrews AR 3rd, Deen TL. Mental health needs and service utilization by Hispanic immigrants residing in mid-southern United States. J Transcult Nurs. 2012; 23(4), 359-368. doi: 10.1177/1043659612451259

4. Byatt N, Biebel K, Friedman L, Debordes-Jackson G, Ziedonis D, Pbert L. Patient's views on depression care in obstetric settings: how do they compare to the views of perinatal health care professionals?. Gen Hosp Psychiatry. 2013; 35(6): 598-604. doi: 10.1016/j.genhosppsych.2013.07.011

5. Cooper LA, Gonzales JJ, Gallo JJ, Rost KM, Meredith LS, Rubenstein LV, et al. The acceptability of treatment for depression among African-American, Hispanic, and white primary care patients. Med Care. 2003; 41(4): 479-489. doi: 10.1097/01.MLR.0000053228.58042.E4

6. Davila M, McFall SL, Cheng D. Acculturation and depressive symptoms among pregnant and postpartum Latinas. Matern Child Health J. 2009; 13(3): 318-325. doi: 10.1007/s10995-008-0385-6
7. Dennis $\mathrm{CL}$, Dowswell T. Psychosocial and psychological interventions for preventing postpartum depression. Cochrane Database Syst Rev. 2013; (2):CD001134. doi: 10.1002/14651858.CD001134.pub3

8. Dwight-Johnson $M$, Sherbourne $C D$, Liao $D$, Wells KB. Treatment preferences among depressed primary care patients. J Gen Intern Med. 2000; 15(8): 527-534.

9. Ennis SR, Rios-Vargas M, Albert NG. The Hispanic Population: 2010. 2011; Census Briefs: U.S. Census Bureau.

10. Evans J, Melotti R, Heron J, Ramchandani P, Wiles N, Murray L, et al. The timing of maternal depressive symptoms and child cognitive development: a longitudinal study. J Child Psychol Psychiatry. 2012; 53(6): 632-640. doi: 10.1111/j.1469-7610.2011.02513.x

11. Field T. Postpartum Depression Effects on Early Interactions, Parenting, and Safety Practices: A Review. Infant Behav Dev. 2010; 33(1): 1-6. doi: 10.1016/j.infbeh.2009.10.005

12. Fournier JC, DeRubeis RJ, Hollon SD, Dimidjian S, Amsterdam JD, Shelton $\mathrm{RC}$, et al. Antidepressant drug effects and depression severity: a patientlevel meta-analysis. JAMA. 2010; 303(1): 47-53. doi: 10.1001/ jama.2009.1943

13. Gavin NI, Gaynes BN, Lohr KN, Meltzer-Brody S, Gartlehner G, Swinson T. Perinatal depression: a systematic review of prevalence and incidence. Obstet Gynecol. 2005; 106(5 Pt 1): 1071-1083. doi: 10.1097/01. AOG.0000183597.31630.db

14. Goodman JH. Women's attitudes, preferences, and perceived barriers to treatment for perinatal depression. Birth. 2009; 36(1): 60-69. doi 10.1111/j.1523-536X.2008.00296.x

15. Grigoriadis S, Vonder Porten EH, Mamisash vili L, Tomlinson G, Dennis CL. Koren $\mathrm{G}$, et al. The impact of maternal depression during pregnancy on perinatal outcomes: a systematic review and meta-analysis. J Clin Psychiatry. 2013; 74(4): e321-341. doi: 10.4088/JCP.12r07968

16. Grote NK, Bridge JA, Gavin AR, Melville JL, lyengar S, Katon WJ. A metaanalysis of depression during pregnancy and the risk of preterm birth, low birth weight, and intrauterine growth restriction. Arch Gen Psychiatry. 2010; 67(10): 1012-1024. doi: 10.1001/archgenpsychiatry.2010.111

17. Heilemann M, Frutos L, Lee K, Kury FS. Protective strength factors, resources, and risks in relation to depressive symptoms among childbearing women of Mexican descent. Health Care Women Int. 2004; 25(1): 88-106. doi: 10.1080/07399330490253265

18. Horowitz JA, Cousins A. Postpartum depression treatment rates for at-risk women. Nurs Res. 2006; 55(2 Suppl): S23-27.

19. Howard LM, Molyneaux E, Dennis CL, Rochat T, Stein A, Milgrom J. Nonpsychotic mental disorders in the perinatal period. Lancet. 2014; 384(9956): 1775-1788. doi: 10.1016/S0140-6736(14)61276-9

20. Kersten-Alvarez LE, Hosman $\mathrm{CMH}$, Riksen-Walraven JM, van Doesum KTM, Smeekens S, Hoefnagels C. Early School Outcomes for Children of Postpartum Depressed Mothers: Comparison with a Community Sample. Child Psychiatry Hum Dev. 2012; 43(2): 201-218. doi: 10.1007/s10578011-0257-y

21. Koutra K, Chatzi L, Bagkeris $M$, Vassilaki $M$, Bitsios $P$, Kogevinas $M$. Antenatal and postnatal maternal mental health as determinants of infant neurodevelopment at 18 months of age in a mother-child cohort (Rhea Study) in Crete, Greece. Soc Psychiatry Psychiatr Epidemiol. 2013; 48(8): 1335-1345. doi: 10.1007/s00127-012-0636-0

22. Kroenke K, Spitzer RL, Williams JB, Lowe B. The Patient Health Questionnaire Somatic, Anxiety, and Depressive Symptom Scales: a systematic review. Gen Hosp Psychiatry. 2010; 32(4): 345-359. doi: 10.1016/j. genhosppsych.2010.03.006

23. Lara MA, Navarrete L, Nieto L, Martin JP, Navarro JL, Lara-Tapia H. Prevalence and incidence of perinatal depression and depressive symptoms among Mexican women. J Affect Disord. 2015; 175: 18-24. doi:10.1016/j.jad.2014.12.035

24. Lara-Cinisomo S, Wisner K.L, Burns RM, Chaves-Gnecco D. Perinatal depression treatment preferences among Latina mothers. Qual Health Res. 2014; 24(2): 232-241. doi: 10.1177/1049732313519866 
25. Leis JA, Heron J, Stuart EA, Mendelson T. Associations between maternal mental health and child emotional and behavioral problems: does prenatal mental health matter?. J Abnorm Child Psychol. 2014; 42(1): 161171. doi: $10.1007 /$ s10802-013-9766-4

26. Lin P, Campbell DG, Chaney EF, Liu CF, Heagerty P, Felker BL, et al. The influence of patient preference on depression treatment in primary care. Ann Behav Med. 2005; 30(2): 164-173. doi: 10.1207/s15324796abm3002_9

27. Nadeem E, Lange JM, Miranda J. Mental health care preferences among low-income and minority women. Arch Womens Ment Health. 2008; 11(2): 93-102. doi: 10.1007/s00737-008-0002-0

28. Reck C, Struben K, Backenstrass M, Stefenelli U, Reinig K, Fuchs T, et al. Prevalence, onset and comorbidity of postpartum anxiety and depressive disorders. Acta Psychiatr Scand. 2008; 118(6): 459-468. doi: 10.1111/j.1600-0447.2008.01264.x

29. Sleath B, West S, Tudor G, Perreira K, King V, Morrissey J. Ethnicity and depression treatment preferences of pregnant women. J Psychosom Obstet Gynaecol. 2005; 26(2): 135-140. doi: 10.1080/01443610400023130A

30. Stein A, Pearson RM, Goodman SH, Rapa E, Rahman A, McCallum M, et al. Effects of perinatal mental disorders on the fetus and child. Lancet. 2014; 384(9956): 1800-1819. doi: 10.1016/S0140-6736(14)61277-0

31. Sutter-Dallay AL, Murray L, Dequae-Merchadou L, Glatigny-Dallay $E$, Bourgeois $\mathrm{ML}$, Verdoux $\mathrm{H}$. A prospective longitudinal study of the impact of early postnatal vs. chronic maternal depressive symptoms on child development. Eur Psychiatry. 2011; 26(8): 484-489. doi: 10.1016/j. eurpsy.2010.05.004
32. Tronick E, Reck C. Infants of depressed mothers. Harv Rev Psychiatry. 2009; 17(2): 147-156. doi: 10.1080/10673220902899714

33. van Schaik DJ, Klijn AF, van Hout HP, van Marwijk HW, Beekman AT, de Haan $M$, et al. Patients' preferences in the treatment of depressive disorder in primary care. Gen Hosp Psychiatry. 2004; 26(3): 184-189. doi: 10.1016/j. genhosppsych.2003.12.001

34. Velders FP, Dieleman G, Henrichs J, Jaddoe VW, Hofman A, Verhulst FC, et al. Prenatal and postnatal psychological symptoms of parents and family functioning: the impact on child emotional and behavioural problems. Eur Child Adolesc Psychiatry. 2011; 20(7): 341-350. doi: 10.1007/s00787-0110178-0

35. Vesga-Lopez O, Blanco C, Keyes K, Olfson M, Grant BF, Hasin DS Psychiatric disorders in pregnant and postpartum women in the United States. Arch Gen Psychiatry. 2008; 65(7): 805-815. doi: 10.1001/ archpsyc.65.7.805

36. Whitton A, Warner R, \& Appleby L. The pathway to care in post-natal depression: women's attitudes to post-natal depression and its treatment. Br J Gen Pract. 1996; 46(408): 427-428. 